\title{
Membrane Separation Technology on Pharmaceutical Wastewater by Using MBR (Membrane Bioreactor)
}

\author{
Saima Fazal*, Beiping Zhang, Zhengxing Zhong, Lan Gao, Xiejuan Lu \\ School of Environmental Science and Engineering, Huazhong University of Science and Technology (HUST), \\ Wuhan, Hubei \\ Email: ${ }^{*}$ saimafazal@hust.edu.cn
}

Received 14 January 2015; accepted 10 April 2015; published 13 April 2015

Copyright (C) 2015 by authors and Scientific Research Publishing Inc.

This work is licensed under the Creative Commons Attribution International License (CC BY).

http://creativecommons.org/licenses/by/4.0/

(c) () Open Access

\begin{abstract}
This study demonstrated the feasibility of implementing of MBR in pharmaceutical wastewater independently, and concluded different applications of MBR in industries. Membrane bioreactor (MBR) technology was a new wastewater treatment technology with a combination of membrane separation technology and biological treatment technology, which had unique advantages on pharmaceutical wastewater treatment. The modified membrane rector design provided a significantly lower concentration of $\mathrm{NH}_{3}-\mathrm{N}$, Phosphorous, Total Nitrogen and $\mathrm{COD}$ around the membranes, and subsequently a more sustainable membrane performance due to much lower overall fouling rates. In this paper, the classification and structure of biological waste water treatment by using MBR technology were summed up along with some examples of MBR in industrial wastewater treatment, which was emphatically analyzed and discussed. Finally, the prospect of MBR in industrial wastewater treatment was described. The industrial wastewater was a high-strength wastewater which had characteristics of complicated constituents, high organics concentration, highly toxic.
\end{abstract}

\section{Keywords}

Membrane Bioreactor, Pharmaceutical Wastewater, Membrane Separation Technology

\section{Introduction}

By the year 2025 it is expected that $60 \%$ of the world population will live with water scarcity if current water consumptions remain at the same current level [1]. It is expected that with further development of human society

\footnotetext{
*Corresponding author.
}

How to cite this paper: Fazal, S., Zhang, B.P., Zhong, Z.X., Gao, L. and Lu, X.J. (2015) Membrane Separation Technology on Pharmaceutical Wastewater by Using MBR (Membrane Bioreactor). Journal of Environmental Protection, 6, $299-307$. 
the need for fresh water will keep increasing. More than $90 \%$ of available fresh water resources will be consumed in the next fifteen years [2]. Therefore, water reuse and reclamation is inevitable in the years to come. The growing use of pharmaceuticals such as antibiotics worldwide, classified as the so called emerging pollutants, has become a new environmental problem, which has raised great concern among scientists in the last few years [3]. At present, there are many different types of industrial waste water. The original type varies with number of production processes, and there are also differences in the synthetic route, thus causing the production of industrial and wastewater composition. Industrial wastewater is usually considered the high concentrations of wastewater, which is characterized by complex components including many kinds of organic pollutants, high values of CODcr and BOD5 and its volatility with differences, high $\mathrm{NH}_{3}-\mathrm{N}$ concentration, large chroma, toxicity and concentrations of high suspended solids [4]. Usually industries have intermittent production and large changes in product categories, which increase the difficulty of industrial wastewater treatment. Industrial wastewater treatment methods commonly used chemical method, chemical and biological methods. Among these methods biological treatment as the most economical, is currently widely used in industrial wastewater treatment. This method has become the focus of research and application. At the current level of domestic and international industrial wastewater treatment there are many reasons to use more SBR (Sequencing Batch Reactor) Act, CASS (Cyclic Activated Sludge System) Act, ICEAS (Intermittent Cycle Extended Aeration), oxidation ditch as the main contact oxidation process, but because of the waste water deposition of inhibitory substances and refractory organics, the treatment effects of these methods are not ideal. Current wastewater technologies will have to be upgraded and/or replaced with new and more advanced water treatment technologies that can provide high quality of treated water, following sustainable practices, being less expensive to operate while meeting more strict legal regulations. The membrane bioreactor (MBR) technology that comprises the activated sludge process and membrane technology has been recognized as a technology for advanced wastewater treatment. In membrane bioreactor technology, the membrane separation technology and bio-organic combination are new technologies of wastewater treatment. It utilizes membrane separation activated sludge and biochemical components of the reaction cell. Organic molecules trapped in place of the secondary settling tank, increase the concentration of activated sludge and ensure water quality, thus greatly strengthening the function of the bioreactor [5].

\section{MBR Reactor Overview}

\subsection{MBR Reactor Component}

Membrane Bioreactor (MBR) process is a hybrid system amalgamating membrane separation with biological treatment. Operating as an MBR allows conventional activated sludge plants to become single step processes, which produce high quality effluent potentially suitable for reuse [6]. In membrane instead of the secondary settling tank, almost all of the activated sludge in the reactor can stay inside, can effectively improve the sludge concentration, sludge concentration up to MBR 18,000 - 19,000 mg/L [7].

Membrane bioreactor (MBR) is a biochemical engineering process involving the use of both 1) a suspended growth bioreactor for biochemical reactions (such as fermentation, bio-oxidation, nitrification, denitrification) and 2) a membrane separator for subsequent solids, liquid separation [8]. Usually the MBR (membrane bioreactor) and the pump membrane consist of three parts. Biologically the reactor and the setting position of the membrane module and the pressure is divided into two parts, external (External) and dip no formula [9] as shown in Figure 1 "External MBR". The mixture inside the biological reactor pumped into the membrane after group parts, the mixture under pressure through the membrane of the water to be processed, and the remaining substance with the concentrated liquid is trapped into the reactor under reflux, filtered water system in the direction from inside to outside. In order to reduce membrane fouling, the higher flow rate of the booster pump and the mixture pressed into the membrane module in the crossflow membrane surface erosion [10]. The other type of membrane is submerged MBR, which is also known as integrated MBR, placed in a bioreactor. The filtrate was sucked out by the pump; a membrane module located at the bottom of the aeration and oxygenation device in addition to a function, strongly stirring the resulting mixture to reduce the surface of the membrane suspension sorptive [11]. The reactor consist of compact structure, small size, low power consumption by surface membrane pore size, and can be divided into microfiltration, ultrafiltration, nanofiltration and a reverse osmosis membrane, which separates the target as shown in Table 1. Microfiltration membrane and ultrafiltration are commonly used in the MBR treatment process. The material is divided into inorganic and organic membrane film, but currently and widely used organic film, which relatively low cost, the manufacturing process is more 


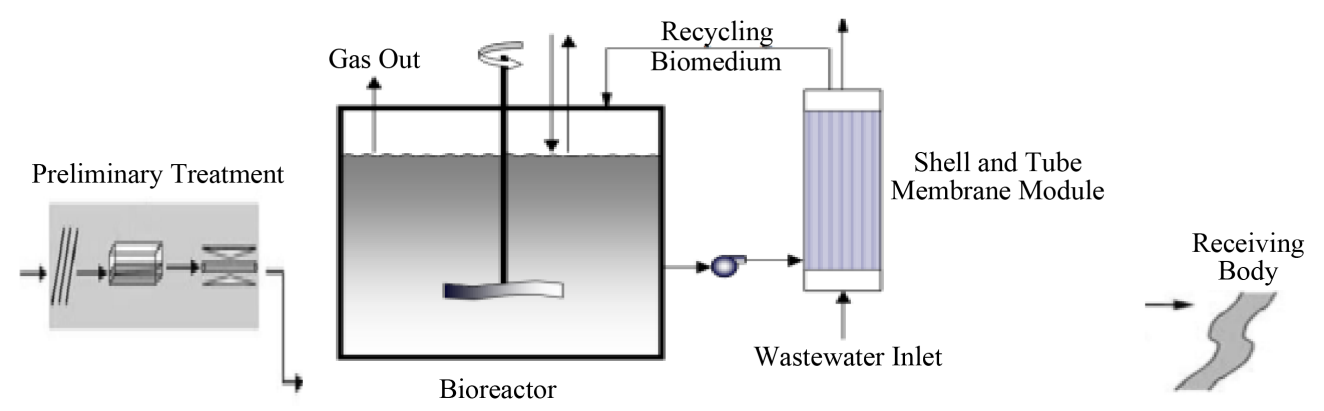

Figure 1. Typical configuration of a treatment plant with membrane bioreactor.

Table 1. Separation characteristics of the membrane separation process.

\begin{tabular}{ccc}
\hline Process & Pressure Difference & Work \\
Microfiltration (MF) & Pressure difference of about $100 \mathrm{KPa}$ & Suspended particles, fibers \\
Ultrafiltration (UF) & $0.1-1.0 \mathrm{MPa}$ pressure difference & Colloidal macromolecules \\
Reverse osmosis (RO) & $0.5-1 \mathrm{MPa}$ pressure difference & Solute, salt \\
Nanofiltration (NF) & & \\
\hline
\end{tabular}

mature, more diverse membrane pore size and style, but during operation easily contaminated, low-intensity and shortlife. The organic film comprises: a polypropylene, polyethylene, polyacrylonitrile, polysulfone, aromatic polyamide, a fluorinated polymer. Inorganic film is a solid film is made of an inorganic material such as metal, metal oxide, ceramic porcelain, long and short glass, zeolites, inorganic polymer materials manufactured into the semi-permeable membrane. In MBR inorganic membranes used mostly ceramic membrane. It's high throughout and having resistance to the pollution, long life, has great competitiveness in the high concentration of industrial wastewater treatment, but in case of alkali inorganic membranes, flexible small and expensive. The membrane structure can be divided according to their hollow fiber, capillary tube, and roll, frame-like. In the external MBR process, plate and frame, tubular and other applications considered, while in the submerged MBR process use of hollow fiber type, frame type is more important.

\subsection{Biological Wastewater Treatment}

Generally, the rate of biological oxygen demand (BOD) removal from the system increases with higher levels of BOD loading. Under high loading conditions, a system can achieve 300 - $400 \mathrm{~kg}$ BOD/ha/d. For yearly averages of BOD removal, a system involving pennywort and/or duckweed is the most effective at lowering BOD. BOD is removed via microbial oxidation in the rhizosphere, water column, and sediments. Aabasi (1987) examined the survival of coliform bacteria in artificial wetlands. Results showed that coliform levels were reduced by 99.1\% after the wetland system. Even if no additional water is needed for the processing, the water which comes in with itself has to be treated in a wastewater treatment plant. This amounts to 3.5 to $5 \mathrm{~m}^{3}$ per t pharma and to $6000-8000 \mathrm{~m}^{3}$ wastewaters per day in a medium sized pharmaceutical factory. For an optimized treatment of the wastewater, it has to be separated into two fractions. The one is the highly polluted so called "flume and washing water" with a high content of organic compounds, mainly sugar and its microbial conversion products. The other is the so called "condensate", which mainly contains heat and ammonia, but only minor amounts of organic compounds. The actual demands for the treatment of the wastewater before releasing it to the next river are fixed in a wastewater regulation ext to the general limit values for the parameters BOD, COD, Ammonia-N, Total-N and $\mathrm{PO}_{4}-\mathrm{P}$, a column with data for special cases is added. Then, if for instance the receiving water needs an enhanced protection, the limit values can be set lower. The phosphate is normally not found in the wastewater and has therefore been added to support microbial growth in the biological plant. The purification effect of the whole wastewater treatment plant concerning the organic compounds (calculated as COD) in general is higher than $99.5 \%$, with remaining COD values of less than $50 \mathrm{mg} / \mathrm{L}$. The total N-elimination effect lies in the range of $85 \%$ - 90\%, with remaining concentrations of 5 - $10 \mathrm{mg} / \mathrm{L}$. The concepts of water reuse and "reclaimed water" have important global consequences. Improved water use patterns would be beneficial in all areas, whether wa- 
ter-limited or not. Regions that regularly face water shortages may be especially affected by the many applications of reclaimed wastewater. Benefits of water reuse in arid (and other) areas include the ability to recycle water for Industry purposes. Water is used each day for activities such as toilet flushing and irrigation. This water is subsequently discharged to the local wastewater treatment facility. If a community faces potable water shortages, many people may question the use of this valued resource in areas that do not necessarily require potable standards health aspects of water reclamation are an immediate concern. If domestic sewage (including human excrement) is to be reused, safety from pathogenic organisms must be under consideration. Faecal coliform, $E$. coli, and Cryptosporidium are a just a few of the well-known organisms that may pose a threat to human health through contamination of the wastewater. This is an obvious barrier to be deal, but social acceptability is another constraint to consider. The public must be informed of the benefits of water reuse, as well as educated about any misconceptions. They must learn to avoid viewing reclaimed water as "sewage", and ideally be given a basic knowledge and faith in the processes of treatment and disinfection.

\section{MBR Advantage in Industrial Wastewater Treatment}

\subsection{High Separation Efficiency, Water Quality Assurance}

Industrial wastewater contains large amounts of suspended material, through the efficient separation membrane, so that suspended solids and turbidity of the water come close to zero. In addition, due to the wastewater contains toxic substances, easily lead to sludge swelling phenomenon occurs at the membrane separation, not resorted to water quality is affected [12].

\subsection{Sludge Concentration, Strong Biochemical Capabilities}

In membrane instead of the secondary settling tank, almost all of the activated sludge in the reactor can stay Inside, can effectively improve the sludge concentration, sludge concentration up to 18,000 - 19,000 mg/L [7] in MBR compared with the traditional process, to improve sludge concentration and in the event of activated sludge bulking avoid wastage because industrial wastewater quality and water has a large amount of volatility, sludge concentration increases, increasing the processing capacity of the reactor force, and can with stand high impact loads [11].

\subsection{Improves Refractory Organics High Purification Efficiency, Shorten the Hydraulic Retention Time}

Industrial wastewater refractory organics are trapped in the reactor to obtain than pass excessive time biological system in contact with the microorganism; certain beneficial microorganisms obligate training and improve refractory organics removal efficiency [13]. In addition due to the biodegradable organic high purification efficiency matter, to ensure the water quality of the premise, MBR can shorten HRT (hydraulic retention time). Dry [5] using self-assembly $300 \mathrm{~L}$ of MBR to cephalosporins pharmaceutical wastewater treatment effluent treated with conventional activated sludge process for comparison. In the COD removal rate under $90 \%$ of the premise, HRT conventional activated sludge process for $80 \mathrm{~h}$, and the MBR of HRT For $35 \mathrm{~h}$. 2.4 conducive to the growth of nitrifying bacteria, good NH3-N removal MBR membrane can not produce $\mathrm{NH}_{3}-\mathrm{N}$ interception, leading MBR has higher $\mathrm{NH}_{3}-\mathrm{N}$ removal rate is mainly due to the large amount of memory nitrification reactor fine bacteria. In membrane separation, the slow growth of nitrifying bacteria in the reactor stayed inside for creating favorable conditions for growth and reproduction of nitrifying bacteria in the large reactor, the amount of the cumulative, so that MBR for $\mathrm{NH}_{3}-\mathrm{N}$ has a high removal efficiency [14]. Using activated sludge process-Hydrolysisacidrogenesis-MBR combined process of a chemical Plant wastewater influent ammonia concentration of $72.8-92.4 \mathrm{mg} / \mathrm{L}$, the results found that almost all ammonia are removed in the MBR tank effluent ammonia concentration is $1.4-4.1 \mathrm{mg} \cdot \mathrm{L}^{-1}$, total removal rate was $94.5 \%-97.6 \%$.

\section{MBR Application Statuses in the Industrial Wastewater Treatment}

\subsection{MBR Applications in Biochemical Wastewater Treatment}

Biochemicals, mainly fermentation engineering, which includes the main waste water produced drainage, drainage aid process, rinse water and domestic sewage. Which is the largest amount of water auxiliary drainage 
process, COD is a direct contribution of the largest drainage process, wash water is important wastewater pollution, its high content of suspended matter. In addition, fermentation class biochemical wastewater nitrogen content $\mathrm{N}$ ratio is high and the low, high sulfate concentrations, high color, containing microbial degradation and difficult with inhibitory substances. [15] reported that the original wastewater treatment system using a vitamin pharmaceutical anaerobic and oxygen, a combination of two contact oxidation process, which is a complex process. In this process aerobic biochemical pool packing easy to plug, the water is unstable and contains large amounts of suspended solids and other shortcomings, so plans to use MBR instead of facultative pond and contact oxidation pond. Table 2 shows the wastewater regulations for the pharma industry.

By using the effective volume of $80 \mathrm{~L}$ of MBR pilot plant test the MBR process for Biochemical wastewater treatment vitamin $\mathrm{C}$ affect as a result, the working conditions and optimized. MBR effluent was found in both conditions can meet emissions standards and working conditions a (DO concentration of $2 \mathrm{mg} / \mathrm{L}$, MLSS of 8000 $\mathrm{mg} / \mathrm{L}$ ) than the two conditions (DO concentration of $3 \mathrm{mg} / \mathrm{L}$, MLSS of 10,000 $\mathrm{mg} / \mathrm{L}$ ) of the treatment effect slightly better, and low running costs. [7] carried out the pilot scale study on the MBR fermentation in industrial wastewater treatment process, wastewater from industrial wastewater station. The pharmaceutical factory mainly produces lincomycin, cordyceps sinensis, medicine, etc., influent COD concentration of $400-1000 \mathrm{mg} / \mathrm{L}$, ammonia is 50 to $110 \mathrm{mg} / \mathrm{L}$. during the test, the MBR HRT gradually adjustand monitor reactor operation. The results show that, MBR of HRT may be reduced to $8 \mathrm{~h}$ without removal of COD and ammonia removal Impact, the effluent COD concentration of 120 - $220 \mathrm{mg} / \mathrm{L}^{-1}$, The effluent ammonia concentration 2 - $15 \mathrm{mg} / \mathrm{L}$. The existing plant and oxygen/aerobic process of HRT for $40 \mathrm{~h}$, the effluent COD concentration of $300-400 \mathrm{mg} / \mathrm{L}$. operating costs and oxygen/aerobic process is 1.1 yuan $\cdot \mathrm{m}^{-3}$, while test equipment only 0.77 yuan $\cdot \mathrm{m}^{-3}$. When comparing the two, the better the treatment effect MBR, transport less line costs. In addition, MBR pilot during lossless film, blocking film phenomenon, membrane workers as normal wash cycle.

\subsection{MBR Applications in Chemical and Industrial Wastewater Treatment}

Chemical and industrial waste including waste liquor category, washing waste, recycling residue, auxiliary the process of drainage and sewage. Table 3 shows the average kinds of wastewater from the pharma production process. Compared with biochemical production wastewater, chemical and industrial wastewater health was smaller, and pollutants clear, relatively few species. But its COD concentration up to hundreds of thousands of milligrams per liter, higher salinity, $\mathrm{pH}$ changes in the larger, some raw materials or products with biological toxicity. Wastewater composition and its single, inadequate nutrition source, develop micro-biological difficulties. [16] for cephalosporin intermediate production enterprises, using contact oxidation-hydrolysis-MBR Syn-

Table 2. Wastewater regulations for the pharma industry.

\begin{tabular}{ccc}
\hline Parameter & Minimum Demands & Special case \\
\hline & $\mathrm{mg} / \mathrm{L}$ & $\mathrm{mg} / \mathrm{L}$ \\
$\mathrm{BOD}_{5}$ & 25 & 25 \\
$\mathrm{COD}$ & 200 & 100 \\
$\mathrm{NH}_{4}$-N & 10 & 10 \\
$\mathrm{~N}_{\text {tot-inorganic }}$ & 30 & 18 \\
$\mathrm{PO}_{4}$-Ptotal & 2 & 2 \\
\hline
\end{tabular}

Table 3. Average kinds of wastewater from the pharma production process.

\begin{tabular}{cccc}
\hline Wastewater & & Flume/washing water & Condensate \\
\hline Spec. Production & $\mathrm{m}^{3}$ to $^{-1}$ pharma & 0.3 & 0.3 \\
$\mathrm{pH}$ & - & $6-11$ & $0.5-9.5$ \\
COD & $\mathrm{g} \cdot \mathrm{L}^{-1}$ & $6-30$ & $0.1-0.4$ \\
N-inorg. & $\mathrm{g} \cdot \mathrm{L}^{-1}$ & $0.02-0.04$ & $0.06-0.2$ \\
Calcium & $\mathrm{g} \cdot \mathrm{L}^{-1}$ & $0.8-4$ & - \\
\hline
\end{tabular}


thetic cephalosporin antibiotic treatment of wastewater. The design of water for $350 \mathrm{~m} \cdot \mathrm{D}^{-1}$, Influent COD concentration of 2125 - 11,561 mg/L. Effluent COD concentration of 79 to $282 \mathrm{mg} / \mathrm{L}$, the effluent BOD5 less than $10 \mathrm{mg} / \mathrm{L}$, to meet the standards of industrial park wastewater sewer (COD $\leq 300 \mathrm{mg} \cdot \mathrm{L}^{-1}$, BOD5 $\leq 100 \mathrm{mg} / \mathrm{L}$ ). [17] reported a pharmaceutical factory in Weifang coagulation-contact oxidation -MBR combination process lisinopril enalapril industrial wastewater, design of water is $500 \mathrm{~m}^{3} \cdot \mathrm{D}^{-1}$, into the average concentration of water COD was $3000 \mathrm{mg} / \mathrm{L}$. In the three months of the commissioning process, the effluent average concentration of COD less than $45 \mathrm{mg} / \mathrm{L}$, the average removal rate of $93 \%$, water quality To meet emission standards, The project operating costs of 1.06 yuan $\cdot \mathrm{m}^{-3}$, recyclable sewage $182,500 \mathrm{t} \cdot \mathrm{a}^{-1}$.

In addition to bio-chemical and chemical industrial waste, there is a class party by physical or chemical extracted from plants and animals or direct the formation of waste production methods namely medicine. [18] describes the use of MBR technology in industrial wastewater treatment plant project in real cases. In Kunming an industrial factory mainly to "seven" as raw materials to produce "seven" series saponins and Paul health products, waste water is $25 \mathrm{~m}^{3} \cdot \mathrm{D}^{-1}$, The COD concentration of $2000 \mathrm{mg} / \mathrm{L}$. Since "Seven" saponins are difficult to handle materials, waste water residues are certain pharmaceutical ingredients will inhibit biological treatment process microbial growth and reproduction, resulting sludge bulking and mining. Conventional biological treatment process is difficult to achieve the desired treatment effect. The use of MBR office management technology will be fully treated effluent reuse. The project was put into use in early 2002, after running 5 a, in early 2007 to replace a domestic film. The project is run by the result of practical experience, come to film making time spent at most 5 a. If the cleaning membrane regeneration process properly, can be extended membrane life. [19] reported an industrial estate Shanghai coagulation sedimentation process-MBR examples of proprietary industrial wastewater treatment works in generated wastewater quality, quantity volatility than large, high chroma and suspended solids containing refractory material. The design of water for $120 \mathrm{~m}^{3} \cdot \mathrm{D}^{-1}$, The COD concentration of $3000-6000 \mathrm{mg} / \mathrm{L}$ engineering since december 2006. The effect of steady production process, the effluent COD concentration were $100 \mathrm{mg} / \mathrm{L}$, the removal rate $98 \%$, all the other indicators are to meet emission standards. Stable operation of the process after handling charges with moderate to 1.76 yuan $\cdot \mathrm{m}^{-3}$.

Figure 2 and Figure 3 also mentioned in Table 4 and Table 5 respectively, which concluded the affective amount of catalyst on the product experimentally, which found that the catalyst of 0.1 to 0.12 pairs of the most significant impact on the viscosity of the product forward; while 0.12 to 0.14 pairs hydroxyl value of the product is not very significant impact; seen, reminders. affect the amount of foam products through experiments found that the amount of foam between 0.8 and 1.0 impact on the value of the most significant product of hydroxyl forward; while the viscosity of between 1.0 to 1.2 on the most significant impact of the product; seen, foam Quantity: $=1 / 1$ alcoholysis agent (mass ratio) is the ratio of the degradation of the most suitable. Figure 4 and Table 6 conclude that typically the chemical degradation method to obtain novel polyols and recovered and the resulting recovered matter is best not to make further separation and purification can be directly used in po-

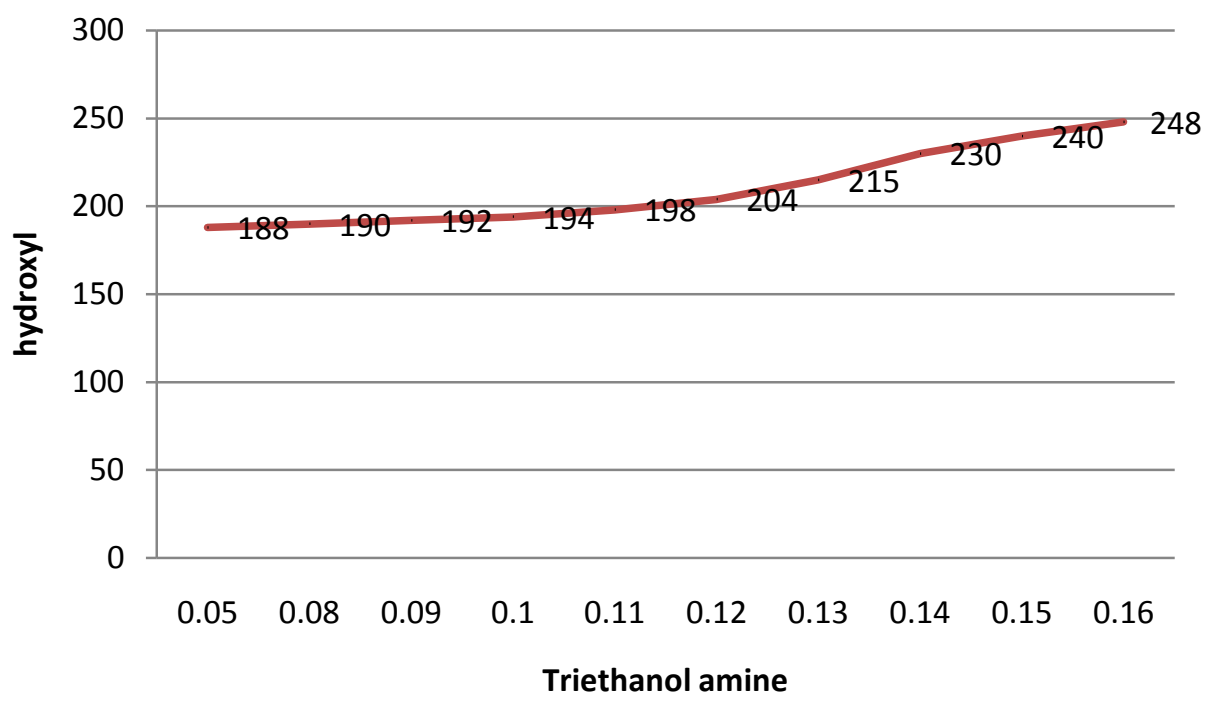

Figure 2. Hydroxl value-catalyst change. 


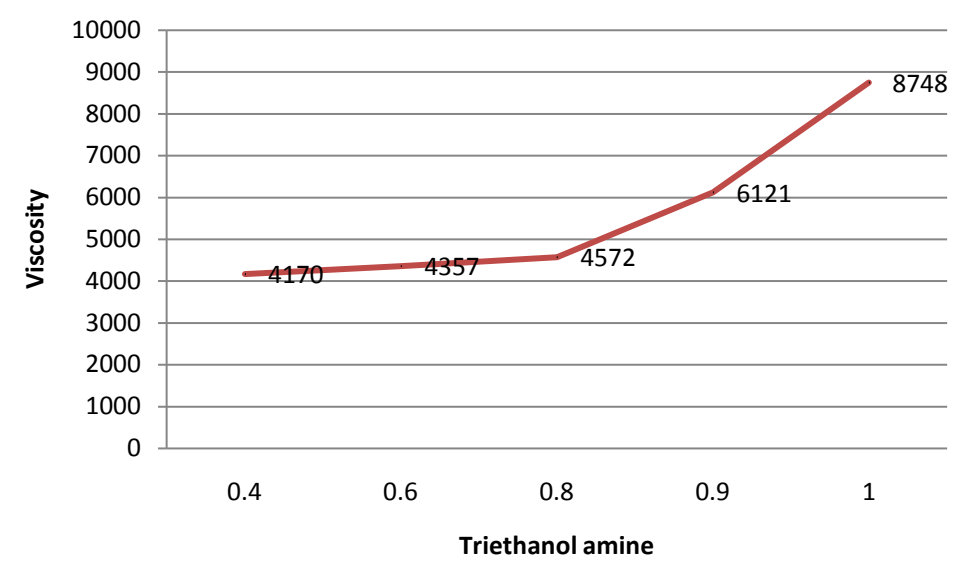

Figure 3. Change in viscosity = rigid.

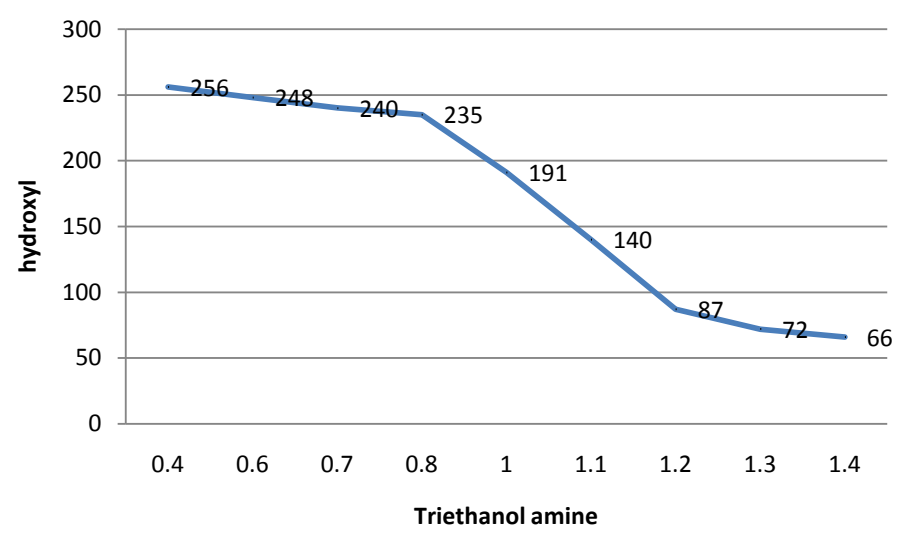

Figure 4. Hydroxl value-rigid change.

Table 4. Impacts of catalyst on viscosity of products.

\begin{tabular}{cc}
\hline Triethanol amine & Viscosity (mPa·s $)$ \\
\hline 0.4 & 4170 \\
0.6 & 4357 \\
0.8 & 4572 \\
0.9 & 6121 \\
1 & 8748 \\
\hline
\end{tabular}

Table 5. Impacts of catalyst on hydroxyl (KOHg) of products.

\begin{tabular}{cc|}
\hline Triethanol amine & Hydroxyl (KOH/g) \\
\hline 0.4 & 256 \\
0.6 & 248 \\
0.7 & 240 \\
0.8 & 235 \\
1 & 191 \\
1.1 & 140 \\
1.2 & 87 \\
1.3 & 72 \\
1.4 & 66 \\
\hline
\end{tabular}


Table 6. Impacts of catalyst on hydroxyl (KOHg) with change values.

\begin{tabular}{cc}
\hline Triethanol amine & Hydroxyl (KOH/g) \\
\hline 0.05 & 188 \\
0.08 & 190 \\
0.09 & 192 \\
0.1 & 194 \\
0.11 & 198 \\
0.12 & 204 \\
0.13 & 215 \\
0.14 & 230 \\
0.15 & 240 \\
0.16 & 248 \\
\hline
\end{tabular}

lyurethane products again production, thus evaluating the major technical indicators recyclables are hydroxyl value, viscosity, and so on. Control each new license rigid foam polyols come to the following conclusions: 1) The amount of the alcohol solution of the catalyst agent, 0.12 (percent by mass) is most appropriate; 2) Foam volume: $=1 / 1$ alcoholysis agent (mass ratio) is the most suitable for the degradation ratio.

\section{Conclusion}

MBR technology as a new sewage treatment process, has a wide range of applications in the industrial wastewater treatment. The characteristics of industrial wastewater treatment by using MBR process have a unique advantage, and gradually it has become a research hotspot technology in recent years in the field of industrial wastewater. There have been some reasons in the laboratory to explore and also have some practical applications in the project. Above examples show various projects, in which MBR process can be applied to practical engineering for industrial wastewater. In some of the existing treatment system facility renovation projects, MBR has also become one of the primary processes. The life issues of membrane and problem of membrane fouling have restricted the MBR process in industrialization, but using new anti-pollution film or taking appropriate action method can reduce the film impact of pollution on the process and effectively extend membrane life. The development of the film material, to improve the film quality of the film and the development of cleaning techniques can also be mitigated to some extent. The modified membrane rector design provided a significantly lower concentration of $\mathrm{NH}_{3}-\mathrm{N}$, Phosphorous, Total Nitrogen and COD around the membranes, and subsequently a more sustainable membrane performance due to much lower overall fouling rates. The problems of membrane fouling compared with the traditional biochemical processes, MBR can guarantee the water quality standards of the wastewater treatment process and also shorten the HRT. The effluent can achieve certain recycling standards in MBR process, which can save energy to a certain extent and lower the operating costs.

\section{References}

[1] Judd, S. (2006) The MBR Book. Elsevier, Amsterdam.

[2] Kraume, M. and Drews, A. (2010) Membrane Bioreactors in Waste Water Treatment-Status and Trends. Chemical Engineering \& Technology, 33, 1251-1259. http://dx.doi.org/10.1002/ceat.201000104

[3] Chatterjee, J., Rai, N. and Sar, S.K. (2014) A Study on Waste Water Treatment from Anti Biotic Production. Current World Environment, 9, 223-226. http://dx.doi.org/10.12944/CWE.9.1.33

[4] F Chrysanthemum Green (2006) Progress Summary Pharmaceutical Wastewater Treatment. Chongqing University of Science and Technology: Natural Science, 8, 13-15.

[5] Jian, W., Shen, B. and Fan, L.H. (2010) Test Membrane Bioreactor Wastewater Treatment Cephalosporin Pharmaceutical Study. Journal of Environmental Engineering, 28 Suppl, 65-66.

[6] Visvanathan, C., Aim, R.B. and Parameshwaran, K. (2000) Membrane Separation Bioreactors for Wastewater Treatment. Critical Reviews in Environmental Science and Technology, 30, 1-48.

http://dx.doi.org/10.1080/10643380091184165 
[7] Min, L.Z. (2010) MBR Process of Fermentation Class Pharmaceutical Wastewater Treatment Pilot Study. Journal of China Water \& Wastewater, 26, 131-133.

[8] Wang, L.K. and Menon, R. (2011) Treatment of Industrial Effluents, Municipal Wastes, and Potable Water by Membrane Bioreactors. In: Membrane and Desalination Technologies, Handbook of Environmental Engineering, Vol. 13, 201-236.

[9] Magara, Y. and Itoh, M. (1991) The Effect of Operational Factors on Solid/Liquid Separation by Ultra-Membrane Filtration in a Biological Denitrification System for Collected Human Excreta Treatment Plants. Journal of Water Science and Technology, 23, 1583-1590.

[10] Chen, W.W. (2007) MBR Membrane Biological Treatment Technology and Its Application and Progress in Wastewater Reuse. Journal of Water Industrial Markets, 8, 52-57.

[11] Chen, X.D., Liang, Y.J. and Li, X. (2004) Research and Application of Membrane Bioreactor Wastewater Treatment. Journal of River North Industrial Science and Technology, 21, 41-44.

[12] Yang, M. and Wang, D.-S. (2010) Experimental Study of Antibiotic Wastewater. Journal of Environmental Protection and Recycling Economy, 9, 54-55.

[13] Bo, F.Y. (1995) Water and Wastewater Treatment Membrane Bioreactor Technology. Journal of Environmental Science, 16, 79-81.

[14] Fan, L.R. (2010) Activated Sludge Process-Combined Process of Hydrolysis Acidification -MBR Chemical Pharmaceutical Wastewater. Journal of Water Supply and Drainage, 36, 158-161.

[15] Feng, F., Zhou, W.B. and Tang, G.L. (2006) MBR Process Vitamin C Pharmaceutical Wastewater Pilot Experiment. Journal of Environmental Engineering, 12, 16-18.

[16] Zheng, W., Chen, L.J., Hai, Y.C., et al. (2010) Contact Oxidation-Hydrolysis-MBR Cephalosporin Antibiotic Treatment Chemical Synthesis Wastewater. Journal of Chemical Environmental Protection, 30, 395-399.

[17] Liu, J., Zhang, M. and Li, J.J. (2007) MBR Process Lisinopril Enalapril Pharmaceutical Wastewater. Journal of Engineers, 5, 27-28.

[18] Sun, M. (2009) MBR Pharmaceutical Wastewater Treatment Process. Journal of Environmental Science Survey, 28, 69-71.

[19] Su, Y.S. and Lin, F.M. (2011) Coagulation and Sedimentation-MBR Pharmaceutical Wastewater Treatment Process. Journal of Water Supply and Drainage, 37, 63-64. 